\author{
Gülşen Akoğlu, \\ Hanife Özer*, \\ Ibrahim İbiloğlu**
}

\section{Dissemine Jüvenil Ksantogranuloma: Bir Olgu Sunumu}

\author{
Disseminated Juvenile Xanthogranuloma: \\ A Case Report
}

Ankara Halil Şıvgın Çubuk Devlet Hastanesi, Deri ve Zührevi Hastalıklar Kliniği, Ankara, Türkiye

*Ankara Halil Şıvgın Çubuk Devlet Hastanesi, Aile Hekimliği Kliniği, Ankara, Türkiye

**Ankara Halil Şıvgın Çubuk Devlet Hastanesi, Patoloji Bölümü, Ankara, Türkiye

Yazışma Adresi/ Correspondence:

Gülşen Akoğlu, Ankara Halil Sıvgın Cubuk Devlet Hastanesi, Deri ve Zührevi Hastalıklar Kliniği, Ankara, Türkiye

E-posta: gusemd@yahoo.com Geliş Tarihi/Submitted: 23.08.2014 Kabul Tarihi/Accepted: 04.09.2014

19-23 Ekim 2010 tarihlerinde Belek Antalya'da gerçekleşen XXIII. Ulusal Dermatoloji Kongresi'nde poster bildirisi olarak sunulmuştur.

@Telif Hakkı 2014 Türk Dermatoloji Derneği Makale metnine www. turkdermatolojidergisi.com web sayfasından ulaşılabilir.

@ Copyright 2014 by Turkish Society of Dermatology - Available on-line at www.turkdermatolojidergisi.com

\section{Sayın Editör,}

Jüvenil ksantogranulom (JXG), genellikle çocukluk ve adölesan dönemde ortaya çıkan nadir bir histiyositik proliferasyondur. Langerhans hücreli olmayan histiyositozların en sık görülen formu olup, etiyolojisi ve patogenezi kesin değildir. Lezyonlarda yer alan histiyositik hücrelerin monosit/makrofaj kaynaklı olduğu düşünülmektedir. "Juvenil ksantogranulom" teriminin içerdiği -ksantoma eki etyopatogenezde yer almayan lipid metabolizma bozukluklarını çağrıştırmasına, erişkin dönemde lezyonların ortaya çıkabilmesine ve JXG'nin hücresel kaynağı hakkında anlaşmazlıkların olmasına rağmen, bu hastalığı tanımlamak için kullanılan JXG terimi genel olarak kabul görmüştür (1). JXG'nin tipik lezyonları asemptomatik, kırmızısarı, genelde kasık, aksilla ve saçlı deri bölgelerinde yerleşen papüllerdir. Hastaların \%80'inde tek bir JXG lezyonuna rastlanmakla birlikte, dissemine form nadir olarak görülmektedir (2).

On sekiz aylık erkek hasta, dermatoloji polikliniğimizde vücutta çok sayıda kabarıklıklar nedeniyle konsülte edildi. Öyküsünden şikayetlerinin üç aylıkken sağ göz kenarında başladığı, birkaç ay içinde hızla tüm vücuduna yayıldığı öğrenildi. Anne babası arasında akrabalık olmayan hastanın ailesinde benzer döküntüleri olan yoktu. Herhangi bir sisteme ait semptomu ve lenfadenopatisi yoktu. Fizik muayenesi doğaldı. Dermatolojik incelemede yüz, gövde ve tüm ekstremitelerinde çok sayıda kahverengi-sarı, keskin kenarlı ve kubbe şeklinde $0.5-1.0 \mathrm{~cm}$ çaplarında papüller görüldü (Resim 1a, b). Darier belirtisi saptanmadı. Oral mukoza ve tırnakları doğaldı. Hastada papüller dışında herhangi bir deri bulgusu yoktu. "Cafe au lait" makülleri görülmedi. Papüllerden birinin histopatolojik incelemesinde epidermiste parakeratotik hiperkeratoz, düzensiz akantoz ve dermoepidermal bileşkeden başlayarak papiller ve retiküler dermisi dolduran Touton tipi dev hücreler izlendi (Resim 2a). Dev hücrelerin nükleusları periferde çelenk şeklinde dizilim göstermekte olup, eozinofilik görünümdeki sitoplazmalarında vakuoller dikkati çekmekteydi (Resim 2b). Dermiste histiyositlerin yanı sıra eozinofil lökositler ve lenfositler de izlendi. Bu tipik klinik ve histopatolojik bulgulara dayanarak hastaya dissemine JXG tanısı kondu. Hastanın tam kan sayımı, eritrosit sedimentasyon değeri,

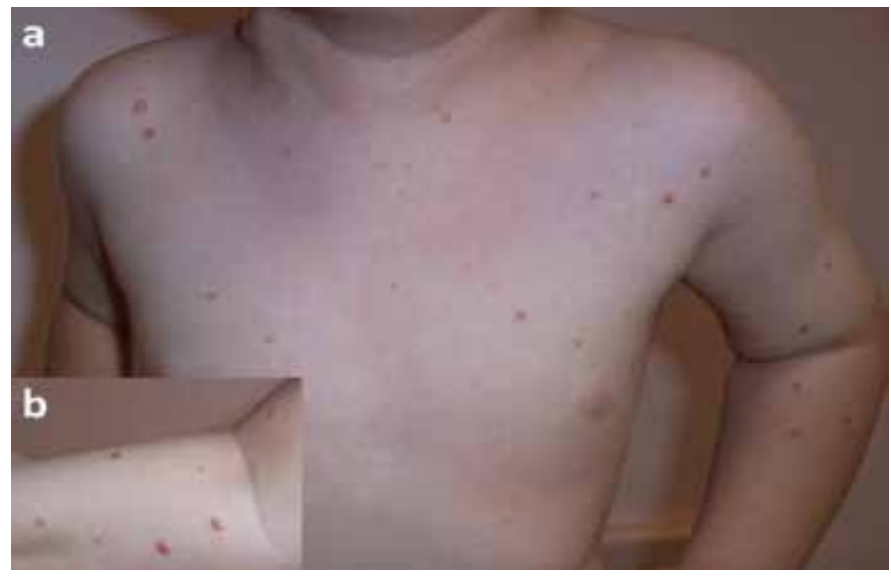

Resim 1. (a) Gövde ve ekstremitelerde çok sayıda kahverengi-sarı, keskin kenarlı ve kubbe şeklinde papüller, (b) Papüllerin yakından görünümü 
karaciğer ve böbrek fonksiyon testleri, açlık kan şekeri ve lipidleri normal sınırlardaydı. Kemik taraması ve abdominal ultrasonografi incelemelerinde patolojik bulguya rastlanmadı. Oftamolojik muayenesi doğaldı. İzleminde sistemik bir sorun gelişmeyen hastanın tüm lezyonları 15 ay sonra kendiliğinden tama yakın geriledi (Resim 3).

JXG'nin ayırıcıtanısındayeralanenönemlihastalık, Langerhans hücreli histiyositoz (LHH)'dur. JXG'nin histopatolojisinde tipik olarak histiyositlerde vakuolizasyon ve çok sayıda çekirdeğin çelenk şeklinde dizildiği Touton tipi dev hücrelerden oluşan granulomatöz yapıların görülmesi tanıyı sağlamaktadır. İmmünohistokimyasal boyamalar sonucunda S100, CD34 ve CD1a boyanmasının gözlenmemesi, JXG'yi LHH'den ayırt ettirmektedir (3). Benign sefalik histiyositoz (BSH) ise Langerhans hücreli olmayan histiyositozlar içerisinde oldukça nadir görülen bir form olup, yanak, alın ve bazen gövde ve kollarda yerleşen çok sayıda sarımsı kırmızı-kahverengi papüllerle karakterizedir. Lezyonlarda vakuollü histiyositler baskındır. Ancak BSH'nin JXG'nin erken bir varyantı olabileceği ve dissemine JXG ile BSH lezyonlarının beraber görülebileceği de öne sürülmektedir (4). Dissemine JXG, çok sayıda lezyonlarla görülebilen ksantom, nörofibrom, molluskum,

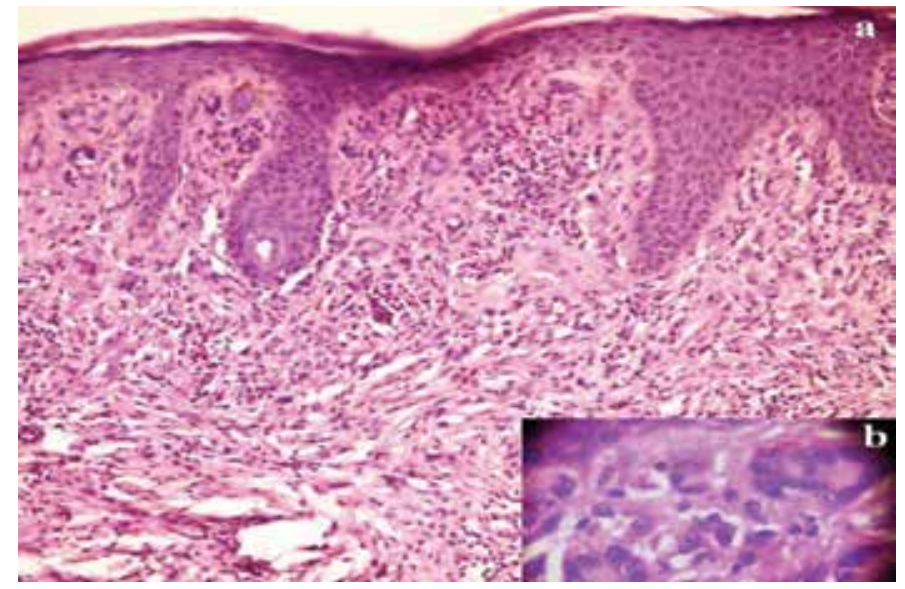

Resim 2. (a) Papiller ve retiküler dermisi dolduran Touton tipi dev hücreler (H\&E, X200), (b) Çekirdekleri çelenk şeklinde dizilen dev hücrelerin yakından görünümü (H\&E, X400)

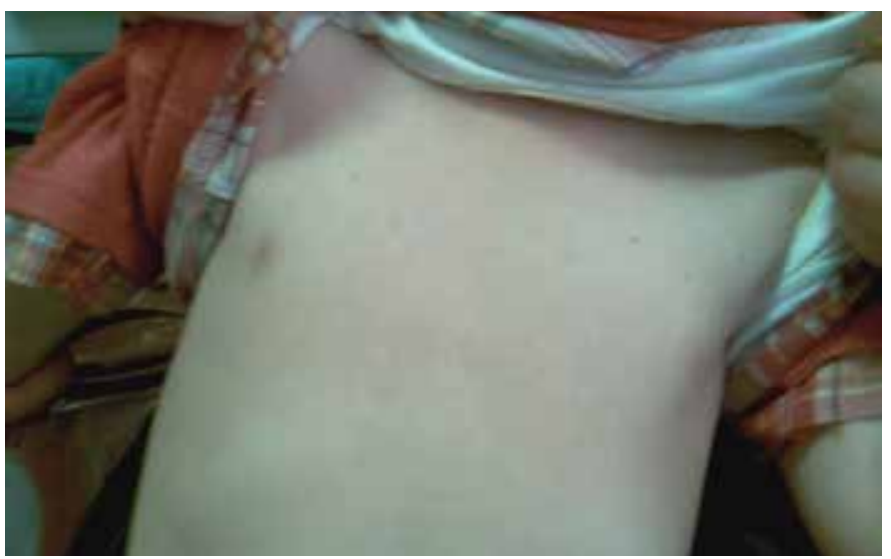

Resim 3. Onbeş aylık izlem sonrası hastanın lezyonlarında görülen tama yakın gerileme ve postinflamatuvar hiperpigmentasyon
Rosai-Dorman sendromu, mastositoz ve jeneralize erüptif dermatofibromlardan hem klinik görünüm hem de tipik histopatolojik bulguları ile kolayca ayırt edilebilmektedir (1). Olgumuzda tipik klinik ve histopatolojik bulgular dissemine JXG tanısını koydurmuştur.

JXG'li hastalarda nörofibromatozis 1 (NF1) birlikteliği olabileceği ve bu durumda jüvenil miyelomonositik lösemi gelişme riskinin JXG'si olmayan NF1'li hastalardan 20-30 kat daha fazla olduğu bildirilmektedir (5). Bu nedenle JXG'si olan kişilerde başta "cafe au lait" makülleri olmak üzere diğer NF1 bulgularının varlığı araştırılmalıdır. Yapılan incelemeler sonucunda olgumuzda NF1'e ait herhangi bir bulguya rastlanmamıştır.

JXG'li 174 olguyu inceleyen Dehler, bu olgular arasında yaşları üç ay ile altı yaş arasında değişen $13(\% 7)$ hastanın baş-boyun, gövde, ekstremite ve skrotum bölgelerinde yaygın deri lezyonları olduğunu bildirmiştir (6). Bu çalışmada, hastalar bir yıl kadar izlenmiş ve hiçbirinde sistemik veya derin organ tutulumu saptanmamıştır. Yaygın lezyonların boyutları aylar ile birkaç yıl içerisinde küçülmesi nedeniyle hiçbir olguya eksizyon önerilmemiştir. Janssen ve ark.' nın incelediği 129 olguluk seride ise hastaların \%81.0'inde tek lezyon saptanmış ve sadece \%3.9'unda sistemik tutulum olduğu görülmüştür (2).

Dissemine JXG'li çocuklarda prognoz genellikle kendiliğinden remisyonla sonuçlanmaktadır. Dolayısıyla bu hastalara "beklegör" stratejisi ile yaklaşımın uygun olacağı önerilmektedir (1). Ancak nadir de olsa karaciğer, dalak, sfenoid kemik, orbital kemik, akciğer, böbrek, kemik iliği, sinir sistemi ve barsak tutulumu olabilmektedir $(3,6)$. Olgumuzda tipik morfolojideki çok sayıdaki yaygın lezyonlar henüz üç aylıkken başlayıp kısa zamanda tüm vücuda yayılımıştır. Bu hızlı yayılma seyri içerisinde hastada herhangi bir sistemik tutulum gözlenmemiştir. Bilindiği kadarıyla daha önce bildirilen Türk olgular içerisinde yaygın JXG lezyonları olan sadece iki olgu bulunmaktadır (7). Olgumuz, lezyonlarının kendiliğinden gerilediğinin görüldüğü uzun süreli izlem sonuçlarını bildirmesi yönünden diğer olgulardan ayrılmaktadır.

Sonuç olarak, dissemine JXG bebeklik döneminde hızla yayılan papüllerle karakterize olabilir. Bu hastalar iç organ tutulumu yönünden araştııımalıdır. Lezyonlar kendiliğinden gerileyebileceğinden dolayı hastaların belirli aralıklarla tedavisiz izlemi uygun olacaktır.

\section{Kaynaklar}

1. Wollina U,BurgdorfWH, HaroskeG. Disseminated juvenilexanthogranuloma. J Dtsch Dermatol Ges. 2006;4:45-8.

2. Janssen D, Harms D. Juvenile xanthogranuloma in childhood and adolescence: a clinicopathologic study of 129 patients from the kiel pediatric tumor registry. Am J Surg Pathol. 2005;29:21-8.

3. Haughton AM, Horii KA, Shao L, et al. Disseminated juvenile xanthogranulomatosis in a newborn resulting in liver transplantation. J Am Acad Dermatol. 2008;58:S12-5.

4. Sidwell RU, Francis N, Slater DN, Mayou SC. Is disseminated juvenile xanthogranulomatosis benign cephalic histiocytosis? Pediatr Dermatol. 2005;22:40-3.

5. Morier $P$, Mérot $Y$, Paccaud $D$, et al. Juvenile chronic granulocytic leukemia, juvenile xanthogranulomas, and neurofibromatosis. Case report and review of the literature. J Am Acad Dermatol. 1990;22:962-5.

6. Dehner LP. Juvenile xanthogranulomas in the first two decades of life: a clinicopathologic study of 174 cases with cutaneous and extracutaneous manifestations. Am J Surg Pathol. 2003;27:579-93.

7. Zindancı I, Kavala M, Can B, et al. A report of three cases. Turkiye Klinikleri J Med Sci 2008;28:576-9. 